\title{
PENERAPAN ALGORITMA MAUT (MULTY_ATTRIBUTE UTILITY THEORY) DALAM PEMILIHAN PUPUK TERBAIK PADA TANAMAN KELAPA SAWIT
}

\author{
Annisa Khairani ${ }^{1}$, Heru Satria Tambunan' ${ }^{2}$ M.Fauzan ${ }^{3}$ \\ ${ }^{1}$ Mahasiswa Program Studi Sistem Informasi, STIKOM Tunas Bangsa Pematangsiantar \\ ${ }^{2,3}$ Dosen STIKOM Tunas Bangsa Pematangsiantar \\ Email: ${ }^{1}$ annisakhairani1406@ gmail.com, ${ }^{2}$ heru@ amiktunasbangsa.ac.id, ${ }^{3}$ mfauzan57@yahoo.com
}

\begin{abstract}
Abstrak
Pupuk adalah suatu bahan yang mengandung satu atau lebih unsur hara atau nutrisi bagi tanaman untuk menopang tumbuh dan berkembangnya tanaman. Perkebunan kelapa sawit menghasilkan keuntungan besar sehingga banyak hutan dan perkebunan lama yang di konversi menjadi perkebunan kelapa sawit. Untuk menghasilkan produksi kelapa sawit yang terbaik di rekomendasikan pupuk yang memiliki kualitas dan kuantitas secara tepat dan cepat agar target pada pekembangan kelapa sawit dapat tecapai dengan maksimal pada poses pertumbuhannya.. Banyak metode yang dapat digunakan untuk menyelesaikan masalah di bidang ilmiah, salah satu nya metode SPK. Peneliti menggunakan metode MAUT (Multy-Attribute Utility Theory) dalam menyelesaikan permasalahan pemilihan pupuk terbaik pada tanaman kelapa sawit berdasarkan beberapa kriteria yang di tetapkan. Aplikasi visual basic 2010 adalah software yang di gunakan pada penelitian ini. Diharapkan penelitian ini dapat merekomendasikan pupuk terbaik yang digunakan pada pihak perkebunan dalam menjaga kualitas tanaman kelapa sawit.
\end{abstract}

Kata Kunci : SPK, MAUT, Visual Basic 2010, MADM, Microsoft Access

\begin{abstract}
Fertilizer is an ingredient that contains one or more nutrients or nutrients for plants to support the growth and development of plants. Oil palm plantations produce large profits so that many forests and old plantations are converted into oil palm plantations. To produce the best palm oil production, it is recommended that fertilizers have the quality and quantity precisely and quickly so that the target in the development of oil palm can be achieved maximally in its growth process. Many methods can be used to solve problems in the scientific field, one of the methods SPK. Researchers used the MAUT (Multy-Attribute Utility Theory) method in solving the problem of selecting the best fertilizer on oil palm plants based on several criteria that were set. Visual Basic 2010 application is the software used in this study. It is hoped that this research can recommend the best fertilizer used on plan tations to maintain the quality of oil palm plants.
\end{abstract}

Keywords : SPK, MAUT, Visual Basic 2010, MADM, Microsoft Access

\section{PENDAHULUAN}

Pupuk adalah material yang ditambahkan pada media tanam atau tanaman untuk mencukupi kebutuhan tanaman yang diperlukan sehingga mampu berproduksi dengan baik. Pupuk juga merupakan makanan (unsur hara) yang sangat dibutuhkan bagi tanaman kelapa sawit. Secara umum pupuk hanya dibagi dalam dua kelompok berdasarkan asalnya, yaitu pupuk anorganik seperti urea (pupuk N), TSP atau SP-36 (P), KCL (pupuk K), dan pupuk organik seperti pupuk kandang, kompos, humus, dan pupuk hijau.

Pada tanaman kelapa sawit, kelapa sawit (Elaeis) merupakan tumbuhan industri penting penghasil minyak, seperti minyak masak, minyak industri, maupun bahan bakar (biodiesel). Perkebunan kelapa sawit menghasilkan keuntungan besar sehingga banyak hutan dan perkebunan lama yang di konversi menjadi perkebunan kelapa sawit. Pemilihan pupuk pada tanaman kelapa sawit tentu perlu dukungan dari perusahaan di PTPN IV Kebun Bah Jambi. Maka perlu penelitian untuk meningkatkan kualitas dan kuantitas produksi pada pupuk secara tepat dan cepat agar target pada perkembangan tanaman kelapa sawit dapat tercapai dengan maksimal pada proses pertumbuhannya. Sumber data ini dikumpulkan berdasarkan data pupuk yang dihasilkan oleh PTPN IV Unit Kebun Bah Jambi yang merupakan Badan Usaha Milik Negara (BUMN). Di Indonesia perkebunan kelapa sawit juga banyak tersebar di berbagai daerah seperti Sumatera, Jawa, Kalimantan dan Sulawesi.

Adapun dasar dari penulis melakukan penelitian ini yaitu untuk mengambil sebuah keputusan dalam pemilihan pupuk pada tanaman kelapa sawit, yang mana pada pemilihan pupuk tersebut diharapkan agar meningkatkan efektivitas pengambilan keputusan terhadap suatu pemecahan masalah dalam pertumbuhan nya pada tanaman kelapa sawit tersebut. Dalam proses pemilihan pupuk, pupuk harus memenuhi kriteria-kriteria yang sudah ditetapkan. Proses pemilihan yang cukup harus disesuaikan dari setiap kriteria-kriteria berdasarkan alternatif yang ada. Permasalahan dalam pemilihan pupuk pada tanaman kelapa sawit tersebut dapat di atasi dengan menggunakan sistem pendukung keputusan (Decision Support System). Dalam hal ini penulis mengambil sebuah algoritma yaitu algoritma MAUT (Multi-Attribute Utility Theory). Penulis memilih metode ini karena algoritma MAUT dapat menghasilkan peringkat pemilihan suatu objek dengan keberhasilan indeks terbaik sampai dengan yang kurang baik.

\section{TEORITIS}

\subsection{Sistem Pendukung Keputusan (SPK)}


Konsep sistem pendukung keputusan pertama kali di perkenalkan pada awal tahun 1970-an oleh Michael S. Scott Morton dengan istilah management decision system. Konsep ini ditandai dengan sistem interaktif berbasis computer yang membantu pengambil keputusan memanfaatkan data dan model untuk menyelesaikan masalahmasalah yang tidak terstruktur [1][2].

\subsection{MADM}

Multiple Attribute Decision Making (MADM) adalah suatu metode yang digunakan untuk mencari alternatif optimal dari sejumlah alternatif dengan kriteria tertentu. Inti dari MADM adalah menentukan nilai bobot untuk setiap atribut, kemudian dilanjutkan dengan proses perankingan yang akan menyeleksi alternatif yang sudah diberikan. Pada dasarnya, ada 3 pendekatan untuk mencari nilai bobot atribut, yaitu pendekatan subyektif, pendekatan obyektif dan pendekatan integrasi antara subyektif dan obyektif. Masing-masing pendekatan memiliki kelebihan dan kelemahan. Pada pendekatan subyektif, nilai bobot ditentukan berdasarkan subyektifitas dari para pengambil keputusan, sehingga beberapa faktor dalam proses perangkingan alternatif bisa ditentukan secara bebas. Sedangkan pada pendekatan obyektif, nilai bobot dihitung secara matematissehingga mengabaikan subyektifitas dari pengambil keputusan [3][4] [5].

\subsection{MAUT (Multi-Attribute Utility Theory)}

Metode MAUT (Multi-Attribute Utility Theory) adalah mendapatkan suatu sistem informasi pendukung keputusan bagi perusahaan dengan tingkat akurasi data yang tinggi dan akan mempermudah proses pemilihan pupuk berdasarkan kriteria tertentu sehingga perkebunan bisa mendapatkan hasil pupuk yang terbaik dan sesuai dengan kebutuhan.

Berikut langkah-langkah dalam proses algoritma MAUT adalah sebagai berikut :

1. Buat kerangka keputusan, dengan mendefinisikan permasalahan.

2. Generate (bangkitkan) alternatif-alternatif yang mungkin dapat memecahkan masalah.

3. Buat daftar (list) semua aspek yang mempengaruhi keputusan.

4. Beri bobot untuk setiap aspek yang ada. Bobot yang ada harus mencerminkan seberapa penting aspek-aspek tersebut terhadap permasalahan.

5. Beri juga bobot dari alternatif-alternatif yang ada. Untuk setiap alternatif, tentukan seberapa memuaskan alternatif tersebut terhadap setiap aspek.

6. Proses evaluasi dari setiap alternatif pada aspek-aspek yang ada untuk mendapatkan keputusan.

Dalam metode Multi-Attribute Utility Theory digunakan untuk merubah dari beberapa kepentingan kedalam nilai numerik dengan skala 0-1 dengan 0 mewakili pilihan terburuk dan 1 terbaik. Hal ini memungkinkan perbandingan langsung beragam ukuran. Yaitu, dengan alat yang tepat, itu memungkinkan saja untuk membandingkan apel dengan jeruk. Hasil akhirnya adalah urutan peringkat dari evaluasi alternatif yang menggambarkan pilihan dari para pembuat keputusan.. Untuk perhitungannya dapat dirumuskan sebagai berikut:

$$
V_{(x)}=\sum_{i=1}^{n} w_{j} \cdot x_{i j}
$$

Secara ringkas, langkah-langkah dalam metode MAUT adalah sebagai berikut:

1. Pecah sebuah keputusan ke dalam dimensi yang berbeda.

2. Tentukan bobot relatif pada masingmasing dimensi.

3. Daftar semua alternatif.

4. Masukkan utility untuk masing-masing alternative sesuai atributnya.

5. Kalikan utility dengan bobot untuk menemukan nilai masing-masing alternatif.

Normalisasi matriks dapat ditentukan dengan rumus:

$$
U_{(x)}=\frac{x-x_{i}^{-}}{x_{i}^{+}-x_{i}^{-}}
$$

Keterangan:

$$
\begin{aligned}
& \mathrm{x}=\text { Bobot alternative } \\
& \mathrm{X}_{\mathrm{i}}^{-}=\text {Bobot terburuk (minimum) dari kriteria ke- } \mathrm{X} \\
& \mathrm{X}_{\mathrm{i}}^{+}=\text {Bobot terbaik (maximum) dari kriteria ke- } \mathrm{X}
\end{aligned}
$$

\section{ANALISA DAN PEMBAHASAN}

\subsection{Proses Perhitungan}

Pada tahap ini adalah proses perhitungan manual dengan menggunakan rumus Metode MAUT (Multy-Attribute Utility Theory). Penulis menentukan pupuk terbaik pada tanaman kelapa sawit di PTPN IV Unit Kebun Bah Jambi. Metode MAUT digunakan untuk pengambilan keputusan berdasarkan nilai preferensi sebagai perangkingan. Berikut ini langkah-langkah dalam mencari smartphone terbaik dengan menggunakan Algoritma MAUT (Multy-Attibute Utility Theory) : 
1. Penentuan data kriteria dan data alternatif

Data alternatif dan kriteria diperoleh dari wawancara langsung untuk menentukan pupuk terbaik pada tanaman kelapa sawit pada perusahaan PTPN IV Kebun Bah Jambi. Berikut ini adalah data kriteria dan data alternatif yang akan digunakan pada penelitian ini adalah sebagai berikut:

a. Data Kriteria

b. Data Altenatif

Tabel 1. Data Kriteria

\begin{tabular}{ll}
\hline Kriteria & Tipe Kriteria \\
\hline Jenis Tanah $(\mathrm{C} 1)$ & Benefit \\
Mudah Di Dapat (C2) & Benefit \\
Kualitas Pupuk (C3) & Cost \\
Menghemat Biaya (C4) & Benefit \\
\hline
\end{tabular}

Tabel 2. Data Alternatif

\begin{tabular}{cc}
\hline Nama Alternatif & Simbol \\
\hline Pupuk KCF & A1 \\
Pupuk Dolomit & A2 \\
Pupuk Kalsit & A3 \\
Pupuk Kalium Magnesium Sulfat & A4 \\
\hline
\end{tabular}

2. Penentuan bobot

Pada tahap ini adalah tahapan dimana proses pemberian bobot untuk setiap kriteria.

Tabel 3. Bobot Kriteria.

\begin{tabular}{ccc}
\hline No & Kriteria & Bobot \\
\hline 1 & Jenis Tanah & 0,23 \\
2 & Mudah Di Dapat & 0,24 \\
3 & Kualitas Pupuk & 0,27 \\
4 & Menghemat Biaya & 0,26 \\
\hline
\end{tabular}

Tabel 4. Data

\begin{tabular}{clcccc}
\hline No & \multicolumn{1}{c}{ Alternatif } & Jenis Tanah & Mudah Di Dapat & Kualitas Pupuk & Menghemat Biaya \\
\hline 1 & Pupuk KCF & Aluvial & Tidak Mudah & Baik & Hemat \\
2 & Pupuk Dolomit & Basalik & Mudah & Baik & Sangat Hemat \\
3 & Pupuk Kalsit & Lotasol & Tidak Mudah & Cukup & Sangat Hemat \\
4 & Pupuk Kalium Mg Sulfat & Sedimen & Tidak Mudah & Baik & Tidak Hemat \\
\hline
\end{tabular}

Tabel 5. Konversi Data

\begin{tabular}{clcccc}
\hline No & \multicolumn{1}{c}{ Alternatif } & Jenis Tanah & Mudah Di Dapat & Kualitas Pupuk & Menghemat Biaya \\
\hline 1 & Pupuk KCF & 4 & 2 & 4 & 4 \\
2 & Pupuk Dolomit & 3 & 4 & 4 & 5 \\
3 & Pupuk Kalsit & 5 & 2 & 3 & 5 \\
4 & Pupuk Kalium Mg Sulfat & 2 & 2 & 4 & 3 \\
\hline
\end{tabular}

3. Normalisasi Pehitungan Matriks

Pada tahap ini dilakukan perhitungan normalisasi matriks keputusan yaitu dengan pembagian bobot alternatif, bobot terburuk (minimum) dari kriteria ke-x dan bobot terbaik (maksimum) dari kriteria ke- $\mathrm{x}$.

$$
U_{(x)}=\frac{x-x i^{-}}{x i^{+}-x i^{-}}
$$

Keterangan :

$U_{(x)}$ : Normalisasi Bobot Alternatif $\mathrm{x}$

$\mathrm{X} \quad$ : Bobot Alternatif

$x i^{-}$: Bobot Terburuk (minimum) dari kriteria ke- $x$

$x i^{+}$: Bobot Terbaik (Maksimum) dari kriteria ke-x

Dimana $\mathrm{U}(\mathrm{x})$ merupakan nilai normalisasi bobot alternatif $\mathrm{x}$, dimana $x i^{-}$merupakan bobot terburuk (minimum) dan $x i^{+}$adalah bobot terbaik (tertinggi) dari setiap kriteria ke-x.

Tabel 6. Nilai Max dan Min

\begin{tabular}{cccccc}
\hline No & Nilai & C1 & C2 & C3 & C4 \\
\hline 1. & Nilai Minimum & 2 & 2 & 3 & 3 \\
\hline
\end{tabular}




\begin{tabular}{llllll}
\hline 2. & Nilai Maksimum & 5 & 4 & 4 & 5 \\
\hline
\end{tabular}

Berikut ini adalah perhitungan Normalisasi Matriks :

$$
\begin{aligned}
& \mathrm{A}_{11}=\frac{4-2}{2-5}=0.67 \\
& \mathrm{~A}_{12}=\frac{2-2}{2-4}=0 \\
& \mathrm{~A}_{13}=\frac{4-3}{3-4}=1 \\
& \mathrm{~A}_{14}=\frac{4-3}{3-5}=0.5
\end{aligned}
$$

Hasil dari keseluruhan dapat dilihat pada tabel berikut :

\begin{tabular}{ccccc}
\multicolumn{5}{c}{ Tabel 7. Tabel Normalisasi Matriks } \\
\hline Alternatif & C1 & C2 & C3 & C4 \\
\hline Alternatif 1 & 0.67 & 0 & 1 & 0.5 \\
Alternatif 2 & 0.33 & 1 & 1 & 1 \\
Alternatif 3 & 1 & 0 & 0 & 1 \\
Alternatif 4 & 0 & 0 & 1 & 0 \\
\hline
\end{tabular}

4. Perkalian Matriks Normalisasi dengan Bobot Kriteria

Penjumlahan hasil perkalian dari hasil normalisasi dengan bobot kriteria pada tahap ini dilakukan penjumlahan hasil perkalian dari hasil normalisasi bobot kriteria. Yaitu elemen baris kriteria ternormalisasi dengan bobot yang sudah ditentukan.

$$
V(X) \sum_{i=1}^{n} W j . X i j
$$

Dimana $V(x)$ merupakan nilai evaluasi dari sebuah objek ke i dan $w_{i}$ merupakan bobot yang menentukan nilai dari seberapa penting elemen ke i terhadap elemen lainnya. Sedangkan $n$ merupakan jumlah elemen.

Untuk mendapatkan nilai - nilai total dari hasil perkalian normalisasi matriks dengan bobot preferensi menggunakan rumus (2.1) yang dapat di lihat pada tinjauan pustaka. Sehingga di dapat nilai total setiap alternatif pada hasil perkalian normalisasi matriks.

$\mathrm{A} 1=(0.67 \times 0.23)+(0 \times 0.24)+(1 \times 0.27)+(0.5 \times 0.26)=0.5541$

$\mathrm{A} 2=(0.33 \times 0.23)+(1 \times 0.24)+(1 \times 0.27)+(1 \times 0.26)=0.8459$

$\mathrm{A} 3=(1 \times 0.23)+(0 \times 0.24)+(0 \times 0.27)+(1 \times 0.26)=0.49$

$\mathrm{A} 4=(0 \times 0.23)+(0 \times 0.24)+(1 \times 0.27)+(0 \times 0.26)=0.27$

5. Menentukan Nilai (Peringkat) Tertinggi

Pada tahap ini di dapatkan hasil perkalian matriks ternormalisasi yang akan menentukan nilai (peringkat) tertinggi dari studi kasus penelitian.

Tabel 8. Hasil Perangkingan

\begin{tabular}{clcc}
\hline No & \multicolumn{1}{c}{ Alternatif } & Jumlah & Rangking \\
\hline 1 & Pupuk KCF & 0.5541 & 2 \\
2 & Pupuk Dolomit & 0.8459 & 1 \\
3 & Pupuk Kalsit & 0.49 & 3 \\
4 & Pupuk Kalium Magnesium Sulfat & 0.27 & 4 \\
\hline
\end{tabular}

\subsection{Penerapan Program Visual Basic}

Pemrosesan data merupakan suatu form untuk memproses data yang telah di input kan ke dalam sistem. Berikut ini merupakan tampilan dari form pemrosesan data pada gambar 1.

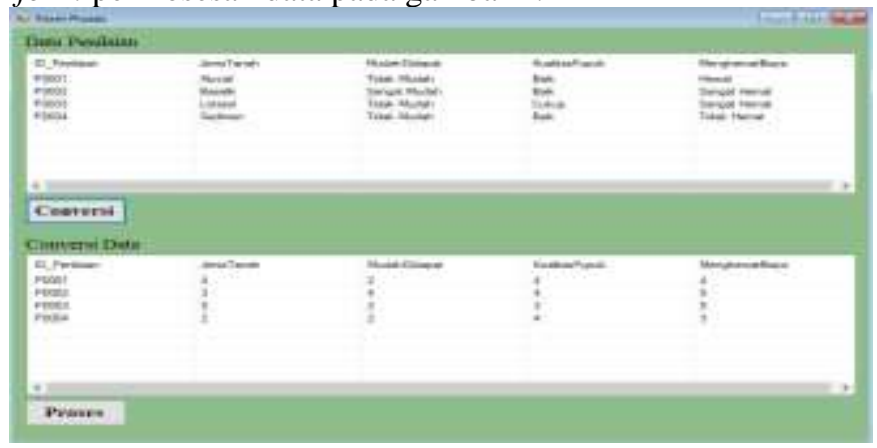

Gambar 1. Form Pemrosesan Data 
Dalam form ini data yang telah di input kan seperti data alternative, data kriteria dan data penilaian, setiap data ini akan di proses menggunakan perhitungan metode MAUT yang telah di inputkan ke dalam sistem, pengguna dapat mengklik tombol proses untuk memproses data sehingga dapat melihat nilai atau hasil dari perhitungan sistem.

Berikut ini adalah hasil proses dari pemrosesan data yang telah di hitung dengan menggunakan metode MAUT (Multy-Attribute Utility Theory) dan dapat dilihat pada gambar 2. Output dari sistem ini adalah laporan hasil dan laporan perhitungan sistem perangkingan yang telah di input kedalam sistem.

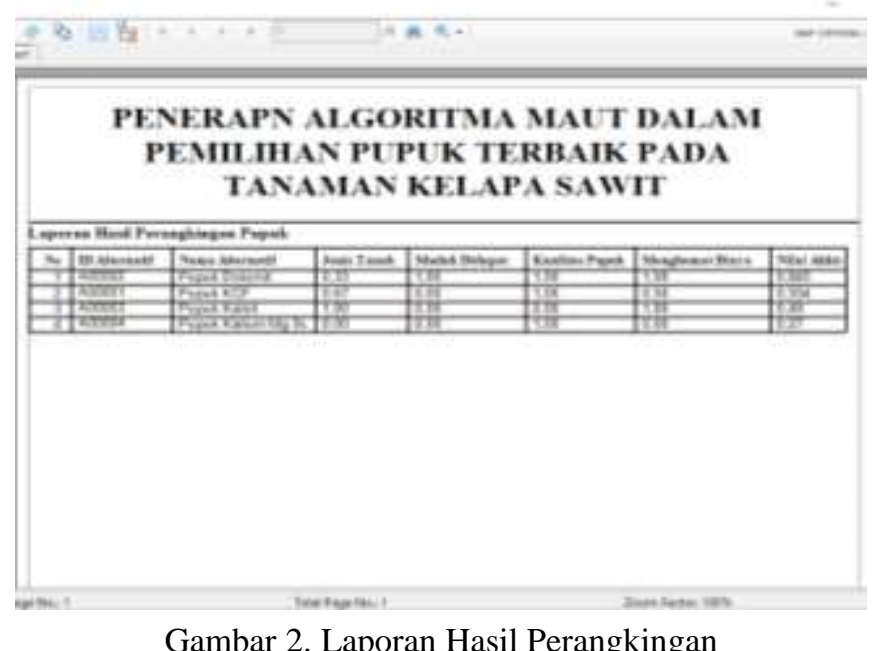

\section{KESIMPULAN}

Berdasarkan hasil penelitian dan pembahasan yang telah dilakukan dapat disimpulkan bahwa metode MAUT (Multy Atributte Utility Theory) dapat di jadikan solusi dalam pemilihan pupuk terbaik di PTPN IV Unit Kebun Bah Jambi serta dapat digunakan sebagai salah satu metode untuk pengambilan suatu keputusan dalam merekomendasikan pemilihan pupuk terbaik pada tanaman kelapa sawit. Dimana kriteria yang digunakan adalah jenis tanah, mudah di dapat, kualitas pupuk, dan menghemat biaya. Perhitungan algoritma MAUT (Multi-Attribute Utility Theory) memiliki perhitungan yang sangat sederhana serta mudah dipahami dan hasil pengujian yang dilakukan antara perhitungan manual dengan perhitungan sistem memiliki validasi yang sesuai.

Berdasarkan hasil penelitian didapatkan beberapa alternatif dengan nilai tertinggi diantara nya yaitu Alternatif 2 dengan nilai 0.8459, Alternatif 1 dengan nilai 0.5541, Alternatif 3 dengan nilai 0.49, dan Alternatif 4 dengan nilai 0.27 yang menjadi penentuan pupuk terbaik di PTPN IV Unit Kebun Bah Jambi. Dalam penyelesaian yang telah dilakukan terdapat hasil pengujian secara otomatis yang dapat membantu permasalahan tersebut dengan menggunakan sistem aplikasi Visual Basic 2010. Dari kesimpulan ini diharapkan menjadi suatu rekomendasi bagi pihak pekebunan kelapa sawit dalam memilih pupuk yang baik pada tanaman kelapa sawit.

\section{REFERENCES}

[1] Mesran, N. Huda, S. N. Hutagalung, Khasanah, And A. Iskandar, Sistem Pendukung Keputusan Pemilihan Supervisor Terbaik Pada Bagian Perencanaan PT. PLN (Persero) Area Medan Menerapkan Preference Selection Index, Komik (Konferensi Nas. Teknol. Inf. Dan Komputer), Vol. 2, No. 1, Pp. 403-409, 2018.

[2] S. Sundari, A. Wanto, And I. Gunawan, Sistem Pendukung Keputusan Dengan Menggunakan Metode Electre Dalam Merekomendasikan Dosen Berprestasi Bidang Ilmu Komputer ( Study Kasus Di Amik \& Stikom Tunas Bangsa ), In Prosiding Seminar Nasional Multi-Disiplin Ilmu (Senasmudi), 2017, Pp. 1-6.

[3] B. A. Wibisono Et Al., Implementasi Metode Weighted Product Untuk, Vol. 1, No. 1, Pp. 130-135, 2018.

[4] A. P. Windarto, Implementasi Metode Topsis Dan Saw Dalam Memberikan Reward Pelanggan, Kumpul. J. Ilmu Komput., Vol. 4, No. 1, Pp. 88-101, 2017.

[5] E. Satria, N. Atina, M. E. Simbolon, And A. P. Windarto, Spk: Algoritma Multi-Attribute Utility Theory ( Maut ) Padadestinasi Tujuan Wisata Lokal Di Kota Sidamanik, Cess(Journal Comput. Eng. Syst. Sci., Vol. 3, No. 2, Pp. 168-172, 2018. 